\title{
College Students' Entrepreneurial Project Human Resource Scheduling
}

\author{
Research \\ Xiaopeng $\mathrm{Li}^{1, \mathrm{a}}$ and Ning Wang ${ }^{2, \mathrm{~b}}$, \\ ${ }^{1}$ Qilu University of technology, Ji'nan,China ${ }^{2}$ Shandong Judges College Ji'nan,China
}

Keywords: Entrepreneurial project; Resource scheduling

\begin{abstract}
In college students' entrepreneurial project,we face a variety of resource allocation,effectively utilize these resources can better improve the efficiency of the operation of the college students' entrepreneurial projects. In this paper, based on the current problems w,we studied the college students venture project human resource scheduling mechanism.Through the system design and software development suggestions, we can make it more effective applied to college students entrepreneurship practice activities and improve college students' entrepreneurial project success rate.
\end{abstract}

\section{Introduction}

With China's current economic development and transition structure adjustment, we need the combination of a variety of operating mode, entrepreneurship is an effective way to transform technology into technology. College students as the carrier of advanced knowledge, through entrepreneurship, can quickly turn school learn into the advanced technology of production activities effectively, and can better improve the production efficiency and upgrade the industrial structure[1]. College students' entrepreneurial activities can also realize college students employment, give many ways to solve the current employment pressure.

But the students' entrepreneurial activities is also facing with many problems, how to solve these problems and improve college students' entrepreneurial project success rate become a hot issue to school and even the country. In college students' entrepreneurial project, facing with a variety of resource allocation, how to effectively utilize these resources can better improve the efficiency of the operation of the college students' entrepreneurial projects[2]. In this paper, based on the current problems we are facing, we studied college students venture project human resource scheduling mechanism, and the system process design and development, and apply it in college students' entrepreneurial activities, improve the success rate of project.

\section{College students entrepreneurial project human resource scheduling system process design}

Entrepreneurial activities organized by the college students' entrepreneurship belongs to the process of a system, process of human resources is not exist independently, it throughout the whole process management for carving, and which can influence each other with other activity in entrepreneurial process and other related business scope, and ultimately affect the overall effect of entrepreneurial activity.

By analyzing the main influencing factors of college students' entrepreneurial organization human resource optimization scheduling, setting up human resource optimization scheduling process and 
main operation mechanism. According to the above analysis[3], we build process build steps as follows:

First, the system of college students' entrepreneurial activity scheduling application settings. First determine the specific plan of the operation of the college students' entrepreneurial projects, according to the college students' entrepreneurial activities existing project planning, integration the relevant resources, carries on the preliminary analysis for human resource scheduling and Settings it. The scheduling system model can determine the specific process of scheduling, and because the college students' entrepreneurial companies' industry has different characteristics of each other, we can develop different scheduling system according to the characters of different industries and enterprises.

Second, according to the scheduling system, we analyze all kinds of projects which the college students' entrepreneurial activities is facing, and then choose the priority of the project. First we determine the key project, according to the scheduler process equipped corresponding resource requirements, and then determine and configuration for the key project resources, and then to other project resources. For the project sorting before in the project we give it the priority scheduling of human resources, so the first thing is to equipped with corresponding human resources for key project, and then choose scheduling rules for the rest of the project. After determining the good order of project resource allocation, scheduling activity is not over, we also need to monitor the operation of the various projects within the whole life cycle of business start-up companies, and use the various tools, such as a variety of analysis tools such as excel, waiting queue, project to analyze project resource scheduling data, according to the analysis result to flexible adjust the scheduling system.

Third, if the scheduling rule before satisfies the requirement of project operation, then enter the staff distribution, according to the project characteristic and the operation rules, for each project configuration the different types of employees. Employees need to pay attention to employee configuration skills, personality characteristics of different factors, such as different projects not only configure the same type of employees. After employees completed, we need to keep track of the project operation, and according to the project performance evaluation rules we evaluated the performance of employees, and give incentives.

\section{College students entrepreneurial project human resource scheduling system Settings}

Based on the development of college students entrepreneurship project resource scheduling system before we determine the specific mode of operation, including three parts content :staff recruitment and management, staff skills assessment and scheduling system to develop and adjust.

Choose the appropriate staff according to the project. First, as a startup the first thing is to form entrepreneurial teams, the choice of employees is very important to the construction of entrepreneurial teams, to ensure that the college students' entrepreneurial companies recruiting employees conform to the requirements of the project, so the first thing to determine is to make sure how many employees is hired, as well as gather hiring information such as the functions of the supervisor and the subordinate.

In addition to identify employee job requirements, we should ensure that staff recruitment can conform to the basic requirement of the job, as well as the basic work flow, etc. With the knowledge management and project management widespread use in enterprise management. For staff position fixed, we can use the job descriptions to record the basic information and the basic requirements of employees required. 
Second, the identification for college students' entrepreneurial enterprises staff job responsibilities[4].

Determine the basic job requirements and recruitment, hiring needs to allocate the basic work items, such as task allocation for the employees, mainly includes the distribution of core work, specific job requirements and the required technical plan, as well as the raw materials and equipment [5]needed for the job to follow the work flow. We need to ensure that the staff positions have to bear the responsibility size and the important degree of the work in the whole project team and position, and the time needed to finish the work[6]. Other employees should not only need to bear the job responsibility, because the team is a whole system, they should help each other and need to make sure in an activity which job is in a dominant position, which job in a position is to assist, these relationships need to be clear.

In the staff recruitment and use, we need to keep people doing with its character and the job matching the basic requirements. The recruitment of staff need to conform to the technical requirements of the job, not only the basic cultural atmosphere matching with the enterprise and the organization, otherwise it will operate on the entire organization and organizational climate impact. So we need to continue examine recruit staff, not only working ability and performance, but also employees' personality and the team cooperation ability, personal interests and hobbies, etc. Because many college students entrepreneurial enterprises will face the school recruit students as a part-time staff, so college students entrepreneurial human resources recruitment needs to consider with the characteristics for the students post setting and quality analysis.

Have a job staff talent assessment and the skill quality assessment. If necessary you can also use the various assessment tools to assist the evaluation work. to assessment staff cannot suitable for employees and jobs. such as to ensure that staff working ability and responsibility, and the quality of staff and work team and organizational culture is consistent .In order to do a good job in human resources scheduling we needs to make the recruitment of staff skills and quality assessment, and investigated that the staff is suitable for enterprise and job requirements. Talent assessment needs to determine the basic principles evaluation and group development strategy, and in this background, [7]according to the information collected by the basic performance of staff skills [8] and quality evaluation.So talent evaluation need to evaluate the content of two aspects, one is the staff working ability evaluation ,the other is a personnel quality evaluation. According to the evaluation results we determine human resource scheduling rules and make reasonable personnel scheduling and allocation.

The main purpose of the talent assessment is to evaluate students' entrepreneurial organization staff work ability and job position requirements consistent. Talent evaluate is not only to grassroots employees evaluated, can also make evaluation of managers which is also an important content of talent evaluation, we not only need to identify the different elements which can influence management efficiency in manager quality assessment, and also can make quality evaluation according to these factors.[9] On the managers quality factor identification, the standard is not unified, such as different requirement between the top managers and the bottom[10]. In addition to evaluate management at present ability on management personnel quality. According to the entrepreneurial organization overall strategy we also evaluate the management personnel comprehensive ability of achieving an organization's strategic objectives which can drive the organization long-term development. 


\section{Conclusions}

In this paper, we combined with the characteristics of college students' entrepreneurial projects, carried on the college students' entrepreneurial project human resource scheduling process design and development. Through the process design system, and develops the corresponding software, can solve a lot of college students' entrepreneurial companies problem such as although technology content is higher, but its' management ability is low, and less the disadvantage of management experience, which can improve the operational efficiency of the college students' entrepreneurial companies. But this article research is preliminary, still can make further detailed human resource scheduling model development and application Settings in the next study of the characteristics on the typical college students entrepreneurial enterprises,, to make it more operable, and can be quickly applied to college students' entrepreneurial activities.

\section{Reference}

[1] Xu Lei, Li Wenyi. Study on the influence factors of the entrepreneurial behavior of college students in our country based on the entrepreneurial process. The progress of science and technology and the Countermeasures of the [J], 2014 (7)

[2] Li Yongqiang et al. Effects of students' entrepreneurial intention TPB model factor analysis based on [J]. Chinese soft science, 2008, (5)

[3] Ching-ching Lin. Enterprise multi-project management of human resource allocation research [D]. Chengdu: southwest jiaotong university, (2006).

[4] Ye etc. A variety of resource allocation between multiple projects of two layers of decision-making method [J]. Journal of systems engineering, 1999 (3), 290-295

[5] Roland B, Martinelly C D, Riane F, et al. Scheduling an operating theatre under human resource constraints[J]. Computers \& Industrial Engineering, 2010, 58(2):212-220.

[6] Estellon B, Gardi F, Nouioua K. High-Performance Local Search for Task Scheduling with Human Resource Allocation[J]. Lecture Notes in Computer Science, 2009, 5752:1.

[7] Plekhanova V. On Project Management Scheduling where Human Resource is a Critical Variable.[J]. Lecture Notes in Computer Science, 1998:116-121.

[8] Zhu Q, Gu Y, Zhang G, et al. An Ant Colony Optimization Model For Parallel Machine Scheduling With Human Resource Constraints[J]. Advances in Intelligent \& Soft Computing, 2010:917-926.

[9] Ghosh J. Distributed task scheduling and human resource distribution in industrial service solution production: a simulation application[J]. International Journal of Production Research, 2013, volume 51(10):2900-2914.

[10] Hai-Qing H E, Xie L Z. Human resource scheduling method based on process-agent[J]. Computer Engineering \& Design, 2010, 31(2):414-409. 